\section{An uncommon cause for severe hypophosphataemia after transsphenoidal pituitary surgery}

\section{Ramamani Mariappan, Arun Prasad, Lashmi Venkatraghavan}

Electrolyte abnormalities are common during the peri-operative period; this can lead to life-threatening cardiac arrhythmias, alteration in mental status, muscle weakness, muscle rigidity and respiratory failure. Failure to recognise these abnormalities may lead to misdiagnosis, which increases the morbidity or mortality. ${ }^{[1]}$ Alteration in serum sodium is the common electrolyte abnormality seen in neurosurgical patients. ${ }^{[2-4]}$ Potassium and calcium abnormalities are also seen but hypophosphataemia is rare, in a healthy patient undergoing surgery. We report a case of acute on chronic hypophosphataemia caused by chronic hypokalaemia, presenting with severe skeletal muscle weakness and paraesthesia, following a transsphenoidal excision of prolactinoma. An informed written consent was obtained from the patient for publication of this case report.

A 41-year-old female (height $166 \mathrm{~cm}$, weight $60 \mathrm{~kg}$ ) was scheduled for an endoscopic transsphenoidal excision of pituitary adenoma. She had presented with galactorrhoea, on investigation, was found to have $1.8 \times 1.3 \times 1.1 \mathrm{~cm}$ prolactinoma. She was treated with oral bromocriptine $1.25 \mathrm{mg}$ once daily, for more than one year duration, which failed to control her symptoms. Her past medical history included hypothyroidism, which was controlled with $50 \mathrm{mcg}$ of levothyroxine per day. She also gave history of heavy vaginal bleeding due to uterine fibroid for which she was on subcutaneous leuprolide acetate injection, an gonadotropin releasing hormone $(\mathrm{GnRH})$ analog, once a month for a year. Her previous anaesthetic history for appendectomy and caesarean section was uneventful. She was a non-smoker and non-alcoholic. Her physical and airway examinations were normal. Pre-operative blood investigations including the thyroid function test were normal except for the serum potassium $\left(\mathrm{K}^{+}\right)$of $3.3 \mathrm{mmol} / \mathrm{L}$.

Her anaesthetic management consisted of intravenous induction with midazolam $(1 \mathrm{mg})$, fentanyl $(150 \mu \mathrm{g})$, propofol (150 mg) and rocuronium (50 mg), followed by endotracheal intubation. Anaesthesia was maintained with air, oxygen, sevoflurane (1MAC) and a low dose of remifentanil infusion $(0.05-0.1 \mu \mathrm{g} / \mathrm{kg} / \mathrm{min})$. Monitoring consisted of 5-lead ECG, non-invasive and invasive blood pressure, pulse oximetry, capnography, oesophageal temperature and urine output. Before surgery, nasal cavity was prepared by packing with epinephrine soaked pledgets $(1$ in 10,000$)$ followed by sub mucosal infiltration of epinephrine (1 in 200,000). Intra-operatively her vitals were stable and end tidal carbon dioxide was maintained within normal limit ( $32-35 \mathrm{~mm} \mathrm{Hg}$ ). The blood loss ( $<250 \mathrm{ml}$ ) was very minimal. She received $2 \mathrm{~L}$ of crystalloids during surgery. Her urine output was $300 \mathrm{ml}$ over $3 \mathrm{~h}$. Intra-operative blood work revealed hypokalaemia $\left(\mathrm{K}^{+} 2.5 \mathrm{mmol} / \mathrm{l}\right)$ and was treated with $40 \mathrm{mmols}$ of potassium chloride $(\mathrm{KCI})$ as an intravenous infusion over $2 \mathrm{~h}$. Her repeat serum $\mathrm{K}^{+}$level was $3.0 \mathrm{mmol} / \mathrm{L}$. At the end of surgery, neuromuscular blockade was reversed and she was extubated awake in the operating room. In the post-anaesthesia care unit (PACU), she was haemodynamically and neurologically stable and received further supplementation of $20 \mathrm{mmols}$ of $\mathrm{KCl}$. Repeat $\mathrm{K}^{+}$revealed persistent hypokalaemia ( $2.4 \mathrm{mmol} / \mathrm{L}$ ) and received another $20 \mathrm{mmol}$ of $\mathrm{KCl}$ and was started with the maintenance fluid of $0.9 \%$ normal saline (NS) with $40 \mathrm{mmol}$ of $\mathrm{KCl}$ at the rate of $100 \mathrm{ml} / \mathrm{h}$. After $4 \mathrm{~h}$ of stay in PACU, she was transferred to neuro critical care step-down unit (NCCU) for monitoring.

Two hours later, she complained of severe weakness of both upper, lower extremities, over the cheeks and could not open her mouth. She also complained that she could not feel her upper, lower extremities and the cheeks. On examination, she was anxious, tachypnoeic, tachycardic (120 bpm), hypertensive $(190 / 110 \mathrm{mmHg})$ and her oxygen saturation was $100 \%$ with the $5 \mathrm{~L}$ of oxygen by a face mask. Her temperature was $37.4^{\circ} \mathrm{C}$ and the arterial blood gas analysis revealed respiratory alkalosis with the $\mathrm{P}_{\mathrm{H}}$ of $7.5, \mathrm{PaCO}_{2}$ of $24 \mathrm{mmHg}, \mathrm{PaO}_{2}$ of $109 \mathrm{mmHg}$ with the $\mathrm{HCO}_{3}$ of $19 \mathrm{mmol} / \mathrm{L}$. Neurological examination revealed severe weakness (grade 2/5) of both extremities.

In view of difficulty in mouth opening with associated tachycardia and hypertension, a clinical possibility of malignant hyperthermia (MH) was considered as one of the differential diagnosis. However, presence of severe muscle weakness instead of muscle rigidity, normothermia

Department of Anesthesia, Toronto Western Hospital, University Health Network, University of Toronto, Toronto, Ontario, Canada

Address for correspondence:

Dr. Ramamani Mariappan, Clinical Fellow, Department of Anesthesia, Toronto Western Hospital, 399, Bathurst Street, Toronto, ON-M5T2S8,

Canada. E-mail: ramamani@cmcvellore.ac.in 
with low $\mathrm{PaCO}_{2}(24 \mathrm{mmHg})$ excluded the possibility of $\mathrm{MH}$. Further investigations revealing a low potassium ( $3.3 \mathrm{mmol} / \mathrm{L})$ and normal creatine kinase of $41 \mathrm{IU} / \mathrm{L}$ with no myoglobin in urine ruled out MH. Rest of her blood investigations including calcium and magnesium were normal except for severe hypophosphataemia with phosphatelevels of $0.28 \mathrm{mmol} / \mathrm{L}$ (normal 0.8-1.45) and mild hypokalaemia $(3.3 \mathrm{mmol} / \mathrm{L})$. Hypophosphataemia was treated with two doses of intravenous potassium phosphate (15 mmol in $250 \mathrm{ml}$ of $0.9 \%$ NS each over 2 hours). Her symptoms improved after correction and she was started with oral supplements of sodium acid phosphate $(500 \mathrm{mg}$ three times daily) and potassium (60-80 mmols/day) for 72 hours. She remained asymptomatic and got discharged from the hospital on the $7^{\text {th }}$ post-operative day in a good clinical state. We did not find any other reports in the literature describing this presentation.

Chronic hypokalaemia has been shown to decrease the renal tubular re-absorption of phosphate thereby increasing the phosphate clearance in urine and can cause hypophosphataemia. ${ }^{[5-7]}$ Studies have shown that a decrease in phosphate clearance and a return of the plasma phosphate concentration to normal levels occurred after correction of the potassium deficit. ${ }^{[7]}$ There was a recent report by food and drug administration (FDA), which showed 78 cases of hypokalaemia among 4487 users of leuprolide acetate for various causes. ${ }^{[8]}$ There are case reports of hypokalaemia after the use of leuprolide acetate for advanced prostatic cancer. ${ }^{[9,10]}$ In our patient, the use of leuprolide acetate may be the possible reason for the chronic hypokalaemia. Chronic hypokalaemia could have been the cause for chronic hypophosphataemia. Intra-operative use of epinephrine, steroid and post-operative anxiety-induced hyperventilation could have caused further decrease in serum phosphate and potassium by intra-cellular shift.

Hypophosphataemia is commonly missed or misdiagnosed due to non-specific signs and symptoms at presentation. ${ }^{[11,12]}$ It can cause considerable morbidity and mortality due to cardio respiratory dysfunction. ${ }^{[13]}$ The common causes for acute hypophosphataemia during the peri-operative period include, fluid shift, drug-induced renal excretion ${ }^{[14]}$ (diuretics) and intra-cellular shift of phosphate (hyperglycaemia, use of insulin, epinephrine and corticosteroid or hyperventilation). ${ }^{[15,16]}$ The common cause for chronic hypophosphataemia is nutritional depletion. However, we did not check phosphate and albumin level during the pre-operative visit as the patient was healthy. Post-operative albumin of $3.3 \mathrm{~g} / \mathrm{dL}$ excluded a nutritional depletion. Hence, chronic hypokalaemia-induced phosphate loss in the urine could be the possible cause for hypophosphataemia in our case. Retrospectively, it was felt that a complete bundle of electrolyte workup should have been done during the immediate post-operative period, which could have prevented the symptoms and the delay in treatment of hypophosphataemia and the intensive care unit (ICU) admission.

Our report presents a case of acute on chronic hypophosphataemia caused by chronic hypokalaemia, manifesting as severe paresthesia and skeletal muscle weakness. Complete electrolyte bundle work up is warranted routinely in surgical patients who present with chronic hypokalaemia.

\section{REFERENCES}

1. Lee JW. Fluid and electrolyte disturbances in critically ill patients. Electrolyte Blood Press 2010;8:72-81.

2. Boscoe A, Paramore C, VerbalisJG. Cost of illness of hyponatremia in the United States. Cost Eff Resour Alloc 2006;4:10.

3. Tisdall M, Crocker M, Watkiss J, Smith M. Disturbances of sodium in critically ill adult neurologic patients: A clinical review. J Neurosurg Anesthesiol 2006;18:57-63.

4. Rabinstein AA, Wijdicks EF. Hyponatremia in critically ill neurological patients. Neurologist 2003;9:290-300.

5. Nicholas JV. Severe hypophosphataemia due to hypokalaemia. JAMA 1971;215:1497-8.

6. Mostellar ME, Tuttle EP Jr. Effects of alkalosis on plasma concentration and urinary excretion of inorganic phosphate in man. J Clin Invest 1964;43:138-49.

7. Anderson DC, Peters TJ, Stewart WK. Association of hypokalaemia and hypophosphataemia. Br Med J 1969;4:402-3.

8. Review: Could Lupron cause Hypokalaemia (Internet). Available from: http://www.ehealthme.com/ [Last updated 2014 Jan 18, Last cited 2014 Jan 25].

9. Metso S, Arola J, Raade M, Valimaki M. Clinico-pathological conference report: Sudden deterioration of general condition, hypokalaemia and diabetes in an elderly man. Duodecim 2012;128:1487-96.

10. Amato R, Stepankiw M, Gonzales P. A phase II trial of androgen deprivation therapy (ADT) plus chemotherapy as initial treatment for local failures or advanced prostate cancer. Cancer Chemother Pharmacol 2013;71:1629-34.

11. Berkelhammer C, Bear RA. A clinical approach to common electrolyte problems, 3: hypophosphataemia. Can Med Assoc J 1984;130:17-23.

12. Imel EA, Econs MJ. Approach to the hypophosphatemic patient. J Clin Endocrinol Metab 2012;97:696-706.

13. Brunelli SM, Goldfarb S. Hypophosphataemia: clinical consequences and management. J Am Soc Nephrol 2007; 18:1999-2003.

14. Liamis G, Milionis HJ, Elisaf M. Medication-induced hypophosphataemia: A review. QJM 2010;103:449-59.

15. Rasmussen A. Hypophosphataemia during postoperative glucose infusion. Acta Chir Scand 1985; 151:497-500.

16. Brautbar N, Leibovici H, Massry SG. On the mechanism of hypophosphataemia during acute hyperventilation: Evidence for increased muscle glycolysis. Miner Electrolyte Metab 1983;9:45-50.

\begin{tabular}{|l|l|}
\hline \multicolumn{2}{|c|}{ Access this article online } \\
\hline Quick Response Code: & Website: \\
\hline & www.jnaccjournal.org \\
\cline { 2 - 3 } & \\
\hline
\end{tabular}

